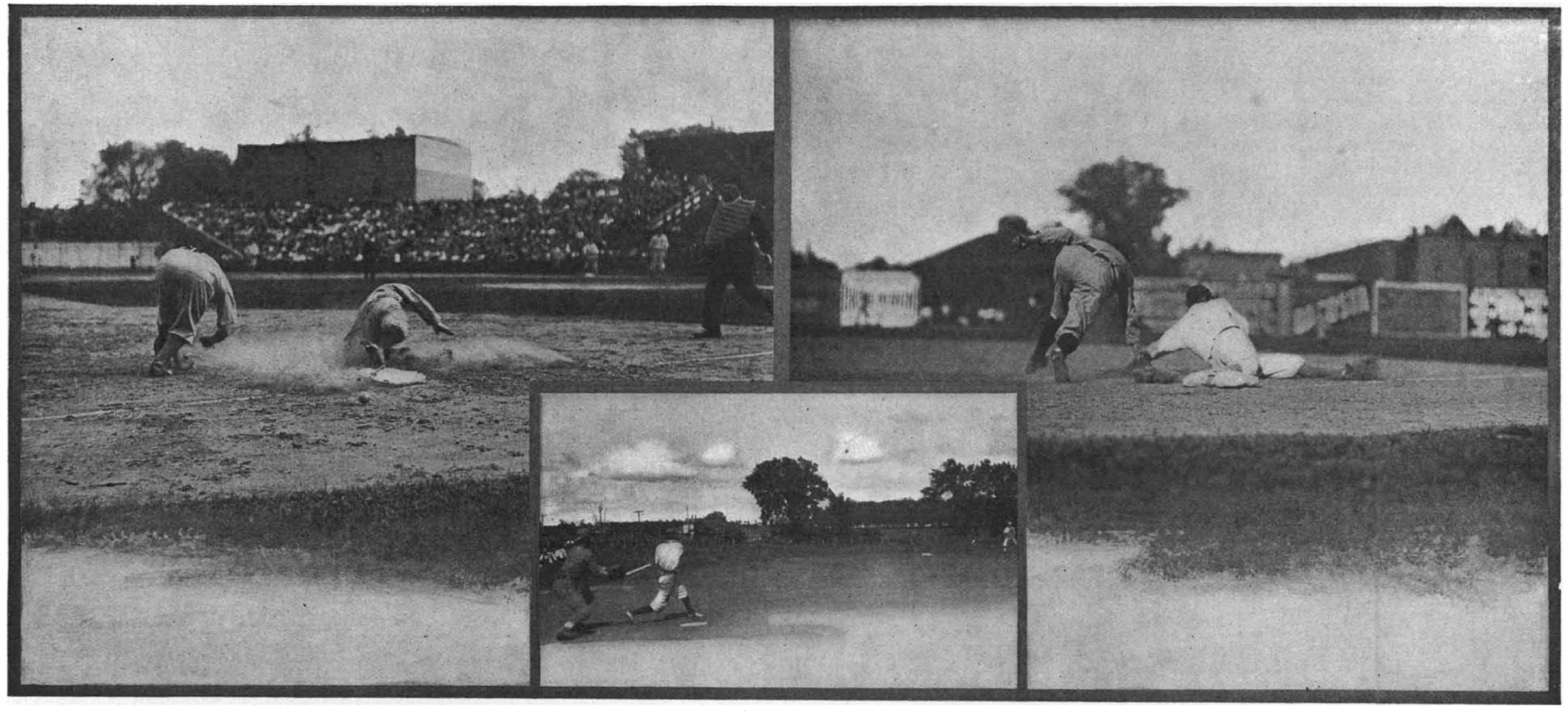

Left-The third baseman has missed a wild throw from the field, and although the ball has passed him ten feet, he has not yet commenced to recover his posiuvil. This illustrates the speed of a thrown ball. Right-Catching a runner napping at first. The slide by the runner gained the time required by the fielder to stoop and touch him. Center-Two out and three on bases, and what he did. The ball is half way to the base, but the catcher's hands are not yet down.

\title{
Time as a Factor in Baseball
}

\section{What Must be Done in a Fraction of a Second}

\author{
By C. H. Claudy
}

THE fathers of baseball builded better than they Tnew when they laid out the first diamond and decided upon the weight and size of balls and bats. The popularity of the game as a spectacle depends largely upon its uncertainty, and its uncertainty depends entirely upon the relation between the distances between bags and the plate, the distance a ball can be batted and thrown, and the time required to make the ball travel, whether propelled by arm or bat

As every "fan" knows, the bases are 90 feet apart. The fastest time ever made about the bases from home to home was $13 \frac{4}{5}$ seconds, and this not during a game. Fifteen seconds about the bases is fast time, or $3 \frac{3}{4}$ seconds between bases with a running start for all except first base. First base has been made from the plate on a bunt and run in $31 / 5$ seconds, but the time is very unusual, 4 seconds flat being good time. Ask a "fan" how fast a ball batted so it strikes the ground in the infield before it is fielded goes on the average. He will guess anywhere from 30 to 300 miles an hour! But hold a stopwatch on all batted balls during a game and count only those which are infield rounders, and you will find that they average about the speed of a fast express train -say 66 miles an hour, or 88 feet per second.

The shortstop will play from 110 to 135 feet from the plate. Suppose he gets an infield grounder 125 feet from the plate. At 88 feet a second, it has taken 1.4 seconds to reach him. Allowing 1.7 seconds for the

throw to first base, he has 0.9 of a second only in which to make the catch, draw his arm back, and make his throw. Yet more men are thrown out at first base on ground balls fielded by the shortstop than ever beat the throw to the first station! The play is almost always close-so close that one of the differences between a good and a poor first baseman is that the good one will reach far forward to get a ball, knowing that reach may make the difference between "safe" and "out!"

It is because of this delicate balance between time of batted ball and throw, and the ability of a man to run 90 feet, that the baseball authorities are so rigid in their requirements of the structure, size and weight of a baseball, and why major league players can play with none but major league balls made by one of two

great firms. They know, these baseball Solons, that a fraction of an ounce difference in weight, a fraction of an inch difference in size, may weigh down the bal ance in favor either of the fielder or the batter-and the balance (and so the uncertainty) must be kept as perfect as possible.

When a man gets on first base, his next thought is of second-the station only 90 feet away, which looks so near and is so far. A good base runner may be able to take a "lead" of 10 feet-though he must needs be very good indeed to do so with a clever pitcher. He may thus reduce the distance between bases to 80 feet. With a standing start, any good base runner should make this distance in 3 seconds. Starting as the pitcher begins to deliver the ball, it would seem easy enough to slide into that bag in 3 seconds time well ahead of the ball. Yet the pitcher, who throws the ball 65 feet $(60.5$ to the plate and 4.5 feet more to the catcher's hands), and the catcher, who must stop it, pick it out of his glove and fire it 124 and frac-

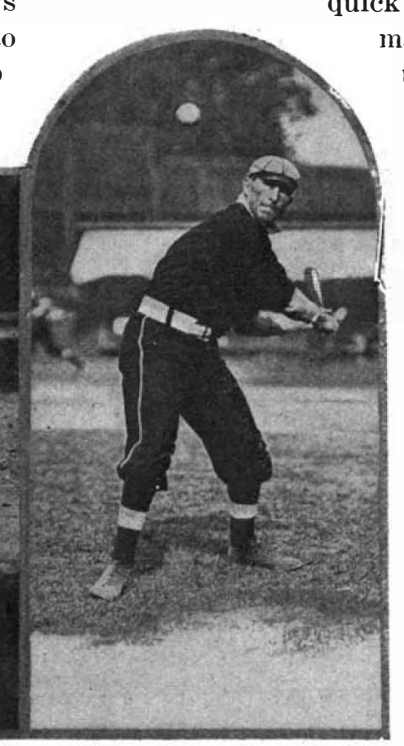

Fungo hitting. greatest height is 8 or 9 feet in the air. Part of his throwing force is put into making the ball climb. Fan who do not know the game sometimes speak of a catcher as throwing "weak" because his throw fades down to the ground at second base. As a matter of fact, the good catcher expects to have his ball reach second base a trifle to his right of the bag and low down. He hopes for this because the minute fraction of time between the fielder's catch at the ball and his dropping his hands to "get" the runner may make the difference between "safe" and "out." For the same reason the base runner slides. He doesn't make quite as fast time sliding as he would running. But he is under the necessity of stopping quickly and "on the quick and sudden stop, and also makes it necessary for the fielder to drop his hands (which takes ime) to touch him. Hence the catcher saves this extra fraction of time with a low throw.

Ask the bleacherite which can be hit the farther, a fast pitch or a slow one, and he will correctly tell you the former. But he won't know why. Were a baseball pitcher infinitely powerful and were he to throw a hundred balls, each time a little faster than the previous time, there would come an instant when the force of the ball forward would be equal to that inherent in the shoulders and bat of the batterthe bat would break, and the ball fall "dead."

But the moder'n pitcher, powerful though he is, is far from that point. The force he puts in his pitch must, physically speaking, be added to the force in the batter's swing. The resultant of the two is the force in the batted ball. If the pitcher pitched with all his force at a stone wall, the ball would rebound. The harder he pitched, the greater the rebound. It is because the rebound is greater from the bat when the stick meets a fast pitch than when it meets a slow one, that the longest hits are made from fast pitching. Of course, fast pitching is hard to hit, because that element of "time" enters again-the batter, expecting one sort of pitched ball, has too small a fraction of a a second after recognizing the pitched ball as a "fast one" to change his mind or "unset" his muscles. Hence (Concluded on page 238.) 


\section{What the Telephone Map Shows}

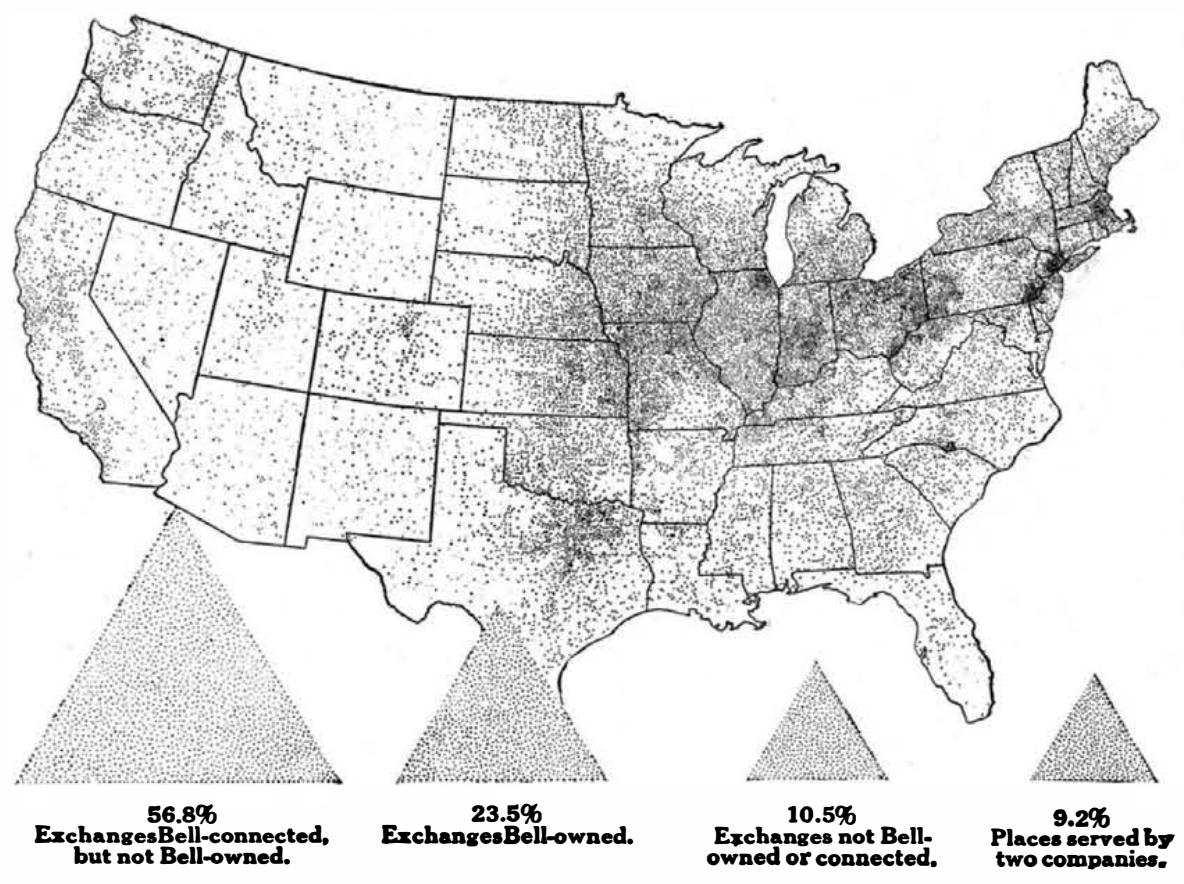

FVERY dot on the map marks a town where there is a teleD phone exchange, the same sized dot being used for a large city as for a small village. Some of these exchanges are owned by the Associated Bell companies and some by independent companies. Where joined together in one system they meet the needs of each community and, with their suburban lines, reach 70,000 places and over $8,000,000$ subscribers.

The pyramids show that only a minority of the exchanges are Bellowned, and that the greater majority of the exchanges are owned by independent companies and connected with the Bell System.

At comparatively few points are there two telephone companies, and there are comparatively few exthere are comparatively few ex-
changes, chiefly rural, which do not have outside connections.
The recent agreement between the Attorney General of the United States and the Bell System will facilitate connections between all telephone subscribers regardless of who owns the exchanges.

Over 8,000 different telephone companies have already connected their exchanges to provide universal service for the whole country.

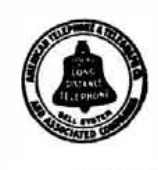

American TELEPHONe and TElegraph Company And Associated Companies.

\section{One Policy One System Universal Service}

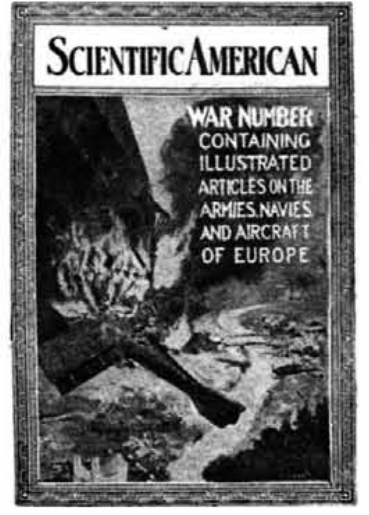

\section{WAR NUMBER SCIENTIFICAMERICAN}

48 PAGES-110 ILLUSTRATIONS

War Map in Four Colors

Size of Map 19 x 14 InCHES

An Authoritive Handbook of the War. Every

Article in this Number is Written by an Expert of National Reputation

\section{ARMY SECTION}

Comparative strength of belligerents.

Their Armament.

Signal and telegraph service.

Medical and ambulance service.

How the vast armies are fed in the field.

Superb illustrations showing all phases of Army, Navy and aerial warfare.

FOR SALE BY ALL NEWSDEALERS, or sent postpaid on receipt of 25 cents

\section{SPECIAL TRIAL SUBSCRIPTION}

For One Dollar we will send the Scientific American to you each week until December 31, 1914, commencing the subscription with the great WAR NUMBER.

MUNN \& CO., Inc., Publishers, 361 Broadway, New York City
An Antomobile Radio-telerraph Station for War Use (Concluded from page 228.) bipolar interrupter, a bipolar circuit breaker, and two safety lamps connected in series between the terminals of the alternator, with the wire between the lamps connected to earth.

For sending wireless messages the sta tion employs an alternating current of 500 cycles, which produces a loud, pure, and constant musical tone. The primary circuit of the sending apparatus is greatly damped by the employment of a divided discharger, which can be regulated with great precision. When the antenna is excited in this way it sends out waves of uniform length which are very easily tuned. As is well known, this uniformity on the damping of the exciting circuit, is entirely independent of the nature of the entirely independent of the nature of the connection, and does not require the circuit to be tuned to exact syntony with
the antenna. The wave-length may then very gradually within wide limits without affecting the transmission of messages. The wave-length can be changed very easily without re-tuning the circuit and the antenna. The energy transmitted to the antenna can be modified very quickly by regulating the sparking distances. This is accomplished by means of a micrometer screw, which acts

simultaneously. discharges are almost silent, a conditio which is particularly desirable for a military field station in war.

The sending apparatus comprises :

1. An oscillating circuit composed of condensers, a discharger, and a resonator.

2. A key having copper contacts im mersed in petroleum oil.

3. A rheostat by which the load on the alternator can be kept constant during transmission.

4. A commutator by which the antenna can be instantly disengaged from the sending apparatus and connected with the receiving apparatus, or conversely, by single movement.

5. An amperemeter which indicates the amount of energy transmitted to the antenna.

The receiving apparatus includes a combination of condensers and resonators which has very little damping, and greatly facilitates the elimination of stray waves The variable condensers contain no dielec tric except air, while the coils are of minimum ohmic resistance and are arranged so as to produce the minimum mutual induction. This combination presents great advantages for the reception of waves of little damping, although its efficiency is not diminished when less syntonizable waves are received. Two definite receiving positions have been adopted: a position of expectation, which is most suitable for rapid exploration of the Hertzian field; and a position of syntony, which makes it possible to obtain great sensitiveness and to eliminate disturbing waves. The station can be adapted to receive signals of any wave-length between 200 and 2.500 meters.

A dynamo and accumulators for electric lighting, and a number of non-electric emergency lamps complete the equipment of this autmobile wireless station, which is as remarkable from the mechanica telegraphy

Time as a Factor in Basebal (Concluded from page 229.) the batter, hitting at an unexpected "fast one" will make a foul (if he hits it at all) more often than anything else. He hits so that his bat meets the ball behind him, not beside him, and it angles off to right or left beyond the foul lines. But when Frank Baker does bring those mighty shoulders against one of Walter Johnson's fast balls - why then it's a home run over the fence!

If further proof is needed, it is found in the amazing fact that the best "arms" in the business can throw a ball farther than the most powerful batter can bat ball tossed-not pitched-in the air. Th bitched-in the air. The by Sheldon Lejeune in 1910. The record batted ball (not made in a game or from a pitched ball, but from a ball tossed in the air by a "fungo" batter) is 419 feet $1 / 2$ inch, made by Edward Walsh in 1911. There is no record of the length of the longest fly batted from pitching, for an excellent reason. A small boy outside the fence always makes off with the ball beore an over-fence home run drive can be measured! It is probably well over 500 eet.

At the rate of 120 feet a second it takes ne half a second for the ball to get from pitcher's hand to the batter at the late. It is the fact that this time is so mall, which accounts for much of the itcher's power over the batter. Half the time a pitcher "fools" a batter it is not because the latter didn't see the curve of the ball or note that the ball was a "float(one pitched slowly), but because there wasn't time for his "nervous reacto work between his recognition of the fact and the instant he must act on is knowledge. A "floater," for instance, The ball seems big-he can see the seams on it. If he knew it was coming before it left the pitcher's hands, he could-and robably would-knock it over the fence. But he has expected a curve or a "fast one." His muscles are all "set." The shoulder muscles tighten and the swing commences almost as the ball leaves the pitcher's hands. Suddenly, when the ball is almost upon him, the batter sees it is "big" and "slow." But that swing is started. The mind has been made up. The brain has telegraphed its instructions. Spite of his will, the bat swings-and after it has passed over the plate, the ball passes lazily by the batter into the catcher's mit

"Psychology," says the professor.

But it actually is time-time and balance between distance, between speed of batted ball and thrown ball, between speed of mind and speed of muscle. While this balance is left undisturbed, baseball will always be uncertain-always be a contest and always have that fascination for the "fan" that it has now-the uncertanity and the hazard epitomized for generations of ball players and fans alike in the aphorism,

"You never know the winner till the ast man's out!"

\section{Switzerland Asks for Help}

THE little Republic of Switzerland is making an appeal to the world for help, for she has been reduced to dire
straits by the terrible IEropean war that is being fought on her borders; and while the appeal is addressed particularly to her children who are enjoying peace and prosperity in other lands, she also seeks as sistance of the many friends who have enjoyed her hospitality in other years.

As a result of the hostilities on her borders. Switzerland has been obliged to mobilize her entire army of 300,000 men, not for offense, but solely to defend her neutrality, at an expense of $\$ 230,000$ a day, while her entire revenues amount to only $\$ 16,000,000$ a year. This heavy expense has not only depleted her exchequer. but with all her able-bodied men in military service her industries are at a standstill and her harvests have had to be left to the feeble hands of the aged, the women and children. The result is that thousands of families are now without the bare necessities of life.

In making this appeal the fact is recalled that Switzerland is the mother country of the Red Cross, and moreover, notwithstanding her own distress, she has offered to become the hospital for the warring nations and to do all in her power to alleviate the sufferings of those injured in battle; and these things should open the hearts of humanity to assist her not only to carry out her charitable purpose but to relieve the distress of her people. Contributions should be sent to Swiss Relief Fund, 241 Fifth Avenue, New York, where subscription lists can also be obtained. The necessities and unmerited suffering of our little sister republic should appeal to the sympathies of all
Americans. 